\title{
Vicious Times
}

\section{Ezio Di Nucci ${ }^{1}$}

Accepted: 20 October 2020 / Published online: 24 October 2020

(C) Springer Nature B.V. 2020

If you are looking for comfort in those vicious times, look no further than academic journals. Those old-fashioned institutions - or should we call them by their new name... those websites take such a long view of things that you will find no trace of COVID-19 in this issue of ETMP - and thank god for that if you ask me.

Still, philosophy in particular has always paid a steep price for its taking of the long view: basically, nobody cares. It is therefore a delight for us to be able to present, in this issue of Ethical Theory and Moral Practice, a philosophical debate that has, at the same time, all the strengths of the rigour, precision and over-the-top clarity commonly associated with analytic philosophy while also preserving the ambition of both using and explaining recent historical cases with all their real-life complexities (rather than fanciful thought-experiments, that is).

Enter so-called vice epistemology. I know, it isn't the sexiest name in the game but isn't that the point of taking the long view? Boring is good, just look at Trump. One of the most influential authors within vice epistemology is surely Quassim Cassam and our journal now publishes a book symposium on Cassam's Vices of the Mind (Cassam 2019): the symposium consists of four commentaries plus author's replies (Alfano 2019; Cassam 2020; Plakias 2020; Tanesini 2020; and Vigani 2020).

Before talking content, let me emphasize that this is the first - but not the last - book symposium of its kind for ETMP: it has been run internally by one of the journal's editors - me - rather than having been submitted as a special issue by an external guest editor. You are always welcome to submit proposals for both special issues and book symposia, by the way, see our CFP.

We run our internal book symposia as follows: the journal's editorial team selects books which are interesting enough from an argumentative point of view to warrant not just a book review or a review essay (which, again, you are welcome to suggest to us) but multiple commentaries, generally between three and five.

The ETMP editorial team then contacts the author (we couldn't do a symposium if an author didn't want to reply to critics, but that hasn't happened yet... wonder why) and selects commentators. This is obviously a different strategy from the classic passive approach of a journal which just has referees evaluate unsolicited submissions but - it is important to stress -

Ezio Di Nucci

ezio@sund.ku.dk

1 University of Copenhagen, Copenhagen, Denmark 
our symposia are part of the book review section of the journal so they do not diminish the page count available to unsolicited submissions.

Also, each contribution to our book symposia is externally peer-reviewed (double-blind) apart from the author's replies, which are just evaluated by ETMP editors - usually at least two. I know, who cares about the inner workings of an academic journal -even more boring than its content, and that's saying something. But, first of all, we have already established that boring is good, remember? And also, we believe that this level of boring transparency might be beneficial, especially for younger colleagues wondering what goes on behind the anonymity of editorial manager systems.

We hope to be able to include one such book symposium in each future issue of ETMP and while that might be a bit ambitious, the next symposium is already planned for the first issue of 2021 (Wallace 2019; Bennett 2019; and Smith 2020) and we are working on others.

Back to vice epistemology. It is - before you get too excited - more about epistemology than it is about vices. The basic idea being that if there are epistemological virtues there must also be logical room for epistemological vices or, to put it another way, a virtue-approach to epistemology can be used - and be beneficial - in both directions. In Cassam's own definition, "Vice epistemology is the philosophical study of the nature, identity, and epistemological significance of intellectual vices. Such vices include gullibility, dogmatism, prejudice, closedmindedness, and negligence. These are intellectual character vices, that is, intellectual vices that are also character traits." (Cassam 2016: 159). Remind you of anybody you know?

I am neither going to try to summarize Cassam's book here nor our own book symposium: after all, shortcuts aren't very academic; it is supposed to take time. I'd rather briefly say what I find fascinating - and also potentially problematic - about virtue/vice approaches: fascinating is inevitably the question of responsibility. Are we responsible for our virtues and vices (and character traits more in general), given that we are supposed to cultivate the former and eradicate the latter?

What account of control do we need in order to be able to say - or maybe indeed in order to not have to say - that we bear responsibility for our epistemic and non-epistemic virtues and vices? I have just finished writing a book about control myself (I won't cite it here so that you can't accuse me of plugging my own stuff;-)), so maybe I'm biased, but that's both a question that I find fascinating and (also) underdeveloped in the literature - which, in fairness, I don't know all too well though. Speaking of what I don't know: I am not an epistemologist but I always found issues around belief voluntarism and attitudinal control intriguing (McHugh 2017).

Another aspect that sometimes goes under when philosophers discuss virtues these days is the Aristotelian original of virtues as habits and, therefore, automatic actions; which bring us right back to the question of control and responsibility above. Ok, enough of the amateur: go and read the pros below to make up your own mind.

\section{References}

Alfano M (2019) Vices of Other Minds. Ethic Theory Moral Prac. https://doi.org/10.1007/s10677-019-10048-0 Bennett C (2019) Russell on naturalism and practical reason. Ethic Theory Moral Prac. https://doi.org/10.1007 /s10677-019-10031-9

Cassam Q (2016) Vice epistemology. Monist 99(2):159-180

Cassam Q (2019) Vices of the mind: from the intellectual to the political. Oxford University Press, Oxford Cassam Q (2020) Vices of the mind: a reply to Alfano, Plakias, Tanesini, and Vigani. Ethic Theory Moral Prac. https://doi.org/10.1007/s10677-020-10128-6 
McHugh C (2017) Attitudinal control. Synthese 194:2745-2762. https://doi.org/10.1007/s11229-014-0643-7

Plakias A (2020) Some probably-not-very-good thoughts on underconfidence. Ethic Theory Moral Prac. https://doi.org/10.1007/s10677-020-10093-0

Smith AM (2020) Responsibility, reactive attitudes, and "the morality system". Ethical Theory Moral Pract. https://doi.org/10.1007/s10677-020-10075-2

Tanesini A (2020) Blaming the intellectually vicious: a critical discussion of Cassam's account of blameworthiness and reprehensibility for epistemic vice. Ethic Theory Moral Prac. https://doi.org/10.1007/s10677-02010092-1

Vigani D (2020) Managing vice. Ethic Theory Moral Prac. https://doi.org/10.1007/s10677-019-10059-x

Wallace RH (2019) The tension in critical Compatibilism. Ethical Theory Moral Pract. https://doi.org/10.1007 /s10677-019-10038-2

Publisher's Note Springer Nature remains neutral with regard to jurisdictional claims in published maps and institutional affiliations. 